\title{
EFEITO DE POPULAÇÕES E ESPAÇAMENTOS SOBRE O POTENCIAL DE RENDIMENTO DA SOJA DURANTE A ONTOGENIA ${ }^{1}$
}

\author{
JOÃO LEONARDO FERNANDES PIRES ${ }^{2}$, JOSÉ ANTONIO COSTA ${ }^{3}$, ANDRÉ LUIS THOMAS ${ }^{4}$ \\ e ANDRÉ ROBERTO MAEHLER ${ }^{5}$
}

\begin{abstract}
RESUMO - O objetivo deste trabalho foi verificar o efeito da redução do espaçamento entre linhas, de populações de plantas e de níveis de fertilidade do solo no potencial de rendimento da soja, em três estádios fenológicos. O trabalho foi conduzido na Estação Experimental Agronômica da Universidade Federal do Rio Grande do Sul, na safra 1996/97, em solo Argissolo Vermelho Distrófico típico. O delineamento experimental foi blocos ao acaso com parcelas subsubdivididas e quatro repetições. Os tratamentos constaram de três níveis de fertilidade do solo (sem adubação, adubação recomendada e duas vezes a adubação recomendada), duas populações (30 e 40 plantas $\mathrm{m}^{-2}$ ) e dois espaçamentos entre linhas ( 20 e $40 \mathrm{~cm}$ ). A cultivar testada foi FT Saray (precoce) sob semeadura direta. O potencial de rendimento médio foi de $15.007 \mathrm{~kg} \mathrm{ha}^{-1} \mathrm{em} \mathrm{R}, 10.282 \mathrm{~kg} \mathrm{ha}^{-1} \mathrm{em} \mathrm{R}_{5}$ e $5.330 \mathrm{~kg} \mathrm{ha}^{-1} \mathrm{em} \mathrm{R}_{8}$ (maturação). Tanto a variação na população de plantas como no espaçamento entre linhas afetaram o potencial de rendimento da soja. A população de 40 plantas $\mathrm{m}^{-2}$ foi superior a 30 plantas $\mathrm{m}^{-2} \mathrm{em}_{5}$, mas tal vantagem não se manteve até a maturação, pois, nesse estádio, não houve diferença significativa entre populações. Com $20 \mathrm{~cm}$ de espaçamento o potencial de rendimento foi maior que com $40 \mathrm{~cm}$ a partir de $\mathrm{R}_{5}$, resultando em maior rendimento em $\mathrm{R}_{8}$.
\end{abstract}

Termos para indexação: Glycine max, etapas de desenvolvimento, componentes de rendimento, população de plantas, fertilidade do solo, desenvolvimento biológico.

\section{EFFECT OF POPULATION AND SPACING ON SOYBEAN POTENTIAL YIELD DURING ONTOGENY}

\begin{abstract}
The objective of this study was to evaluate the effects of the row spacing reduction, plant populations and soil fertility on soybean potential yield at three stages of development. The experiment was performed at the Estação Experimental Agronômica of Universidade Federal do Rio Grande do Sul, in Eldorado do Sul, Rio Grande do Sul State, Brazil, in the 1996/97 growing season, in a Rhodic Paleudult soil . The experimental design was a split split-plot randomized complete block, with four replicates. Treatments were tested at three soil fertility levels (without fertilization, the recommended fertilization and twice the recommended fertilization), two plant populations (30 and 40 plants $\mathrm{m}^{-2}$ ) and two row spacing $(20$ and $40 \mathrm{~cm}$ ). The cultivar tested was FT-Saray (early), in notill. Mean potential yields were $15.007 \mathrm{~kg} \mathrm{ha}^{-1}$ in $\mathrm{R}_{2}, 10.282 \mathrm{~kg} \mathrm{ha}^{-1}$ in $\mathrm{R}_{5}$ and $5.330 \mathrm{~kg} \mathrm{ha}^{-1}$ in $\mathrm{R}_{8}$ (maturity). Plant populations as well as row spacing affected the soybean potential yield. The population of 40 plants $\mathrm{m}^{-2}$ was greater than the 30 plants $\mathrm{m}^{-2}$ in $\mathrm{R}_{5}$ but this advantage was not observed at maturity, because at this stage there was no difference between populations. With $20 \mathrm{~cm}$ rows the potential yield was greater than with $40 \mathrm{~cm}$ in $\mathrm{R}_{5}$, resulting in higher yield in $\mathrm{R}_{8}$.
\end{abstract}

Index terms: Glycine max, developmental stages, yield components, plant population, soil fertility, biological development.

\footnotetext{
${ }^{1}$ Aceito para publicação em 6 de janeiro de 2000.

Extraído da dissertação de mestrado apresentada pelo primeiro autor à Universidade Federal do Rio Grande do Sul (UFRGS), Porto Alegre, RS.

${ }^{2}$ Eng. Agrôn., M.Sc., Dep. de Plantas de Lavoura, Faculdade de Agronomia, UFRGS, Caixa Postal 776, CEP 90001-970 Porto Alegre, RS. Bolsista do CNPq.
}

E-mail: piresj1@vortex.ufrgs.br

${ }^{3}$ Eng. Agrôn., Ph.D., Prof. Titular, UFRGS. Bolsista do CNPq. E-mail: lueska@zaz.com.br

${ }^{4}$ Eng. Agrôn., M.Sc., Prof. Assistente, UFRGS. E-mail: thomaspl@vortex.ufrgs.br

${ }^{5}$ Eng. Agrôn., aluno do curso de mestrado, UFRGS. Bolsista do CNPq. E-mail: amaehler@ig.com.br 


\section{INTRODUÇÃO}

O crescimento e desenvolvimento de culturas agrícolas são limitados por fatores como restrição da atividade biológica a uma estreita faixa de temperatura, disponibilidade de energia solar para promover a fixação de $\mathrm{CO}_{2}$ e a imposição de estresses abióticos, especialmente o suprimento inadequado de água (Sinclair, 1994).

O potencial de rendimento da soja é determinado geneticamente e quanto deste potencial vai ser atingido depende do efeito de fatores limitantes que estarão atuando em algum ponto durante o ciclo (Costa, 1996). O efeito desses fatores pode ser minimizado pela adoção de um conjunto de práticas de manejo que faz com que a comunidade de plantas tenha o melhor aproveitamento possível dos recursos ambientais disponíveis.

Inúmeros trabalhos sugerem métodos para estimar o rendimento máximo de diferentes culturas (Loomis \& Williams, 1963; Doorenbos \& Kassam, 1979; Bugbee \& Salisbury, 1988; Camargo et al., 1988), levando em consideração fatores ambientais como radiação solar, concentração de $\mathrm{CO}_{2}$ e disponibilidade hídrica.

Em soja, estimativas do potencial de rendimento podem ser feitas durante a ontogenia por meio da quantificação das estruturas reprodutivas da cultura (flores e legumes), possibilitando verificar o efeito de diferentes práticas sobre a produção e fixação dessas estruturas.

Trabalhando com essa perspectiva, Ventimiglia et al. (1999) relatam que se todas as flores presentes em $R_{2}$ (florescimento) se transformassem em legumes o rendimento poderia ter sido de $18.000 \mathrm{~kg} \mathrm{ha}^{-1}$, ao passo que se todos os legumes formados até $R_{5}$ (início do enchimento de grãos) alcançassem a maturação o rendimento seria de $10.000 \mathrm{~kg} \mathrm{ha}^{-1}$, enquanto o rendimento alcançado em $R_{8}$ foi de $4.600 \mathrm{~kg} \mathrm{ha}^{-1}$. Esse potencial foi influenciado por diferentes níveis de fertilidade do solo ( 3 e 15 ppm de fósforo) e por espaçamentos entre linhas $(20$ e $40 \mathrm{~cm})$.

A soja apresenta características de alta plasticidade, ou seja, capacidade de se adaptar às condições ambientais e de manejo, por meio de modificações na morfologia da planta e nos componentes do rendimento. A forma com que tais modifica- ções ocorrem pode estar relacionada com fatores como a fertilidade do solo, população de plantas e espaçamento entre linhas, sendo importante suas interações para conhecer qual o arranjo conjunto dessas práticas traria respostas mais favoráveis no rendimento da lavoura.

O uso de adubação elevada, população de plantas adequada ( 40 plantas $\mathrm{m}^{-2}$ ) e espaçamento estreito $(20 \mathrm{~cm})$, de forma combinada, poderiam levar à obtenção de maiores potenciais de rendimento.

Este trabalho teve por objetivo avaliar o efeito da redução no espaçamento entre linhas, de populações de plantas e de níveis de fertilidade do solo, no potencial de rendimento da soja, em três estádios fenológicos.

\section{MATERIAL E MÉTODOS}

O experimento foi conduzido na Estação Experimental Agronômica da Universidade Federal do Rio Grande do Sul (EEA/UFRGS), localizada no município de Eldorado do Sul, região fisiográfica da Depressão Central do Estado do Rio Grande do Sul. O clima da região pertence à variedade específica Cfa da classificação de Köppen, subtropical úmido com verão quente e o solo, de acordo com Embrapa (1999), pertence à unidade de mapeamento São Jerônimo, classificado como Argissolo Vermelho Distrófico típico.

O delineamento experimental foi o de blocos ao acaso com parcelas subsubdivididas, com quatro repetições. Como tratamentos, utilizaram-se três níveis de fertilidade do solo (fertilidade atual - sem adubação -; adubação recomendada; duas vezes a adubação recomendada), nas parcelas principais; duas populações de plantas (30 e 40 plantas $\mathrm{m}^{-2}$ ) nas subparcelas, e dois espaçamentos entre linhas $(20$ e $40 \mathrm{~cm}$ ) nas subsubparcelas. Utilizou-se a cultivar FT-Saray de ciclo precoce e hábito de crescimento determinado como cultivar reagente.

$\mathrm{O}$ experimento foi instalado sob semeadura direta em solo contendo cobertura de $5,8 \mathrm{t} \mathrm{ha}^{-1}$ de matéria seca de aveia-preta (Avena strigosa) e milho (Zea mays L.), no momento da semeadura.

A adubação foi efetuada de acordo com as recomendações da Rede Oficial de Laboratórios de Análise de Solos ROLAS (Bartz, 1994). As parcelas que receberam o tratamento denominado fertilidade atual não foram adubadas. A adubação nas demais parcelas foi realizada com semeadora, em linhas distanciadas em $20 \mathrm{~cm}$, no sentido perpendicular ao das linhas de semeadura. Não foi realizada adubação na linha de semeadura pela possibilidade de proble- 
mas com salinidade, principalmente quando da utilização do dobro da adubação recomendada.

A recomendação de adubação indicou a quantidade de $55 \mathrm{~kg} \mathrm{ha}^{-1}$ de $\mathrm{P}_{2} \mathrm{O}_{5}$ e $40 \mathrm{~kg} \mathrm{ha}^{-1}$ de $\mathrm{K}_{2} \mathrm{O}$. Para suprir essa necessidade, foram aplicados $200 \mathrm{~kg} \mathrm{ha}^{-1}$ de adubo da fórmula 5-20-20, mais $33 \mathrm{~kg} \mathrm{ha}^{-1}$ de superfosfato triplo (46 kg ha-1 de $\mathrm{P}_{2} \mathrm{O}_{5}$ em $100 \mathrm{~kg}$ de adubo). Dobrou-se a dose nas parcelas que receberam o tratamento com o dobro da recomendação, para tentar maximizar o rendimento.

As sementes foram tratadas com fungicida recomendado para soja e infectadas com estirpes específicas de Bradyrhizobium japonicum, em meio turfoso. A semeadura ocorreu dia 9/11/96, com a utilização de implemento montado para semear cereais de estação fria. Quando as plantas estavam no estádio $\mathrm{V}_{4}$ (quarto nó, segundo Costa \& Marchezan, 1982) realizou-se o desbaste, ajustando-se as populações de plantas para os valores desejados nos tratamentos (30 e 40 plantas $\mathrm{m}^{-2}$ ).

O ensaio foi mantido livre da concorrência de pragas e plantas daninhas. Para tanto, foram utilizados produtos específicos recomendados para a cultura. Realizou-se a suplementação hídrica por meio de irrigação por aspersão, mantendo os níveis de umidade do solo adequados para o crescimento da cultura $(0,5 \mathrm{bar})$.

As subsubparcelas tinham dimensão de $4 \times 5 \mathrm{~m}$, considerando-se como bordadura uma linha em cada extremidade lateral e $0,5 \mathrm{~m}$ em cada cabeceira.

Para estimar o potencial de rendimento da soja durante a ontogenia, realizaram-se determinações em cinco plantas marcadas em sequiência na linha, de cada subsubparcela, fazendo-se as determinações sempre nas mesmas plantas quando atingiram os estádios $\mathrm{R}_{2}$ (florescimento), $\mathrm{R}_{5}$ (início do enchimento de grãos) e $R_{8}$ (maturação), de acordo com a escala proposta por Costa \& Marchezan (1982). Foram quantificados os números de flores em $\mathrm{R}_{2} \mathrm{e}$ de flores e legumes em $\mathrm{R}_{5}$. Em $\mathrm{R}_{8}$, determinou-se a porcentagem de legumes com um, dois, três grãos e sem grãos, e o peso de 100 grãos de legumes com um, dois e três grãos. Os dados obtidos em $\mathrm{R}_{8}$ foram utilizados para calcular o rendimento no final do ciclo e o potencial de rendimento em $\mathrm{R}_{2}$ e $\mathrm{R}_{5}$, quando aplicados aos valores de flores e legumes obtidos nesses estádios. Essa estimativa é a representação do rendimento que seria obtido se a planta conseguisse manter todas as flores presentes em $R_{2}$ e todas as estruturas presentes em $R_{5}$ (flores e legumes), e que estas flores e legumes chegassem ao final do ciclo com a mesma proporção de legumes com um, dois e três grãos, legumes sem grãos e com o mesmo peso de 100 grãos daqueles obtidos no estádio $\mathrm{R}_{8}$. Nesse caso considera-se que não haveria limitação de assimilados (fonte) para suprir essa demanda (flores e legumes).
A caracterização dos nós, ramos, flores e legumes foi realizada segundo a metodologia proposta por Marchezan (1982).

O número de legumes com um, dois, três grãos e sem grãos foi obtido pela contagem desses legumes na amostra de cinco plantas por parcela e depois transformados para $\mathrm{m}^{2}$ e porcentagem. O peso de 100 grãos foi realizado em amostra de 25 grãos, oriundos de legumes com um, dois e três grãos, separadamente.

Os resultados obtidos foram submetidos à análise de variância, e as diferenças entre tratamentos foram testadas pelo teste de Tukey, a 5\% de probabilidade. No que se refere aos dados de fertilidade do solo, que apresentavam três níveis, as comparações foram feitas por análise de regressão.

\section{RESULTADOS E DISCUSSÃO}

Considera-se potencial de rendimento, no contexto deste trabalho, como o possível rendimento que a cultura da soja obteria se as condições ambientais fossem adequadas, dentro do sistema de cultivo e práticas de manejo adotadas, possibilitando a fixação máxima das estruturas reprodutivas produzidas pela planta e presentes nos estádios avaliados. É diferente do rendimento potencial, por este representar o potencial genético da cultura, não podendo ser estimado, ao menos que se consiga quantificar a contribuição de cada gene da planta para o rendimento de grãos.

Em soja, busca-se maximizar o potencial de rendimento desde o início do ciclo. Para isso, deve-se estabelecer adequada população de plantas e proporcionar o desenvolvimento de caule, ramos, raízes e área foliar de modo que produzam maior número de estruturas reprodutivas. Além disso, para um rendimento elevado, esse potencial deve manter-se o mais estável possível até o estádio de maturação $\left(\mathrm{R}_{8}\right)$.

O método utilizado para estimar o potencial de rendimento da soja levou em conta, basicamente, a produção e fixação de estruturas reprodutivas (flores e legumes). A forma com que essas estruturas são fixadas pode ser explicada por duas teorias. Uma, indica que a fixação é limitada pela fonte ou tem uma limitação nutricional (causada pela capaci-

Pesq. agropec. bras., Brasília, v.35, n.8, p.1541-1547, ago. 2000 
dade fotossintética) e a outra, indica um controle hormonal, em que as estruturas mais desenvolvidas, ou com prioridade de demanda, teriam, além de maior força de demanda, a capacidade de enviar mensagens, inibindo a fixação de estruturas menos desenvolvidas. Esse comportamento é exemplificado por Heitholt et al. (1986), que sugerem haver uma grande abscisão de legumes produzidos durante os estádios finais do período reprodutivo da soja.

A estimativa do potencial de rendimento usada neste trabalho é um método de cálculo mais realista do que os métodos que consideram os fatores limitantes em níveis adequados, pois, até certo ponto, leva em conta o efeito desses fatores (de solo e de planta), por meio de sua interação na produção e fixação de estruturas reprodutivas. A planta, pela integração de todos os fatores, expressa o potencial de rendimento em cada momento que o mesmo foi determinado.

Se todas as flores presentes em $R_{2}$ tivessem gerado legumes, e estes chegado à maturação, o potencial de rendimento médio, estimado nesse estádio, teria sido de $15.007 \mathrm{~kg} \mathrm{ha}^{-1}$. Por sua vez, se todas as flores e legumes presentes em $\mathrm{R}_{5}$ tivessem chegado à maturação, o potencial de rendimento médio nesse estádio teria sido de $10.282 \mathrm{~kg} \mathrm{ha}^{-1}$. O rendimento médio em $\mathrm{R}_{8}$ foi de $5.330 \mathrm{~kg} \mathrm{ha}^{-1}$. Esses níveis de potencial de rendimento e rendimento alcançado refletem as condições adequadas predominantes durante a condução do experimento, principalmente pelo suprimento hídrico adequado, demonstrado pelo balanço hídrico, obtido segundo Thorntwaite \& Mather (Ometo, 1981) (Fig. 1).

$\mathrm{O}$ potencial de rendimento foi influenciado pelo espaçamento entre linhas e população de plantas no estádio $\mathrm{R}_{5}$, ambos em efeito simples (Fig. 2), não havendo interação entre fatores nem resposta diferenciada em função da variação dos níveis de fertilidade do solo.

A falta de resposta no potencial de rendimento à elevação na adubação, de zero para duas vezes a dose recomendada, pode estar associada à falta de resposta da soja ao aumento na adubação no primeiro ano, em virtude do baixo aproveitamento de nutri-

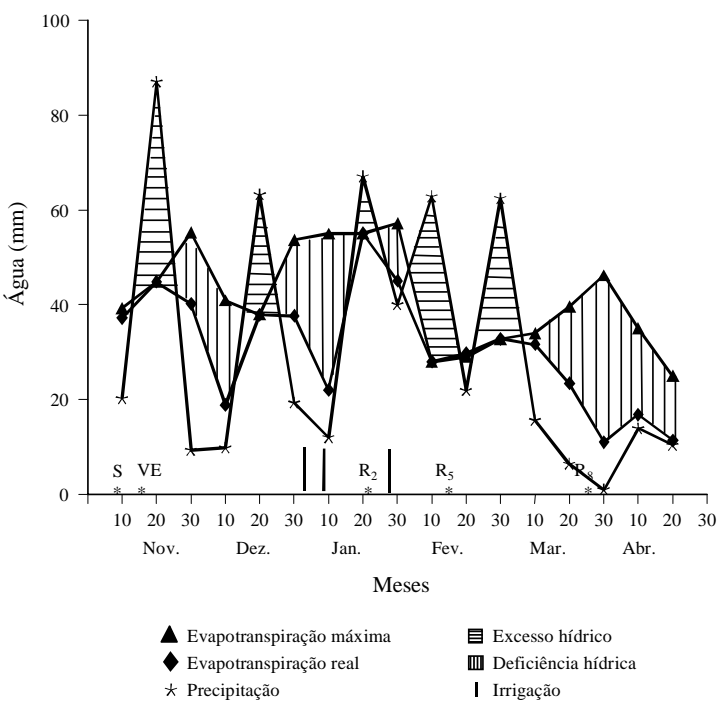

FIG. 1. Balanço hídrico para capacidade de armazenamento de água na profundidade de solo $50 \mathrm{~mm}$, nas épocas de semeadura (S), emergência (VE), florescimento $\left(\mathbf{R}_{2}\right)$, início do enchimento de grãos $\left(R_{5}\right)$ e maturação $\left(R_{8}\right)$ de soja cultivar FT Saray. EEA/UFRGS, Eldorado do Sul, RS, 1996/1997.

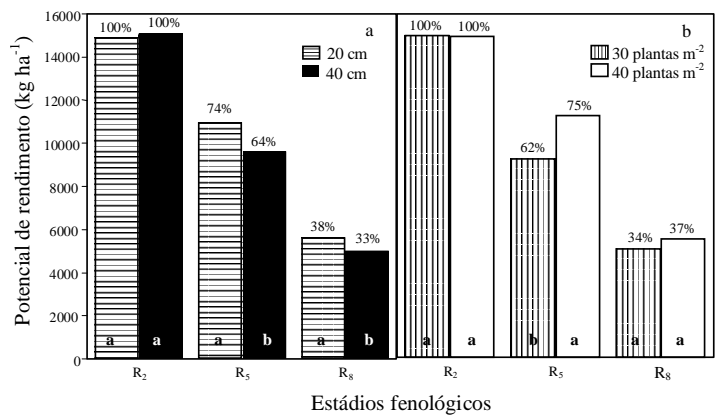

FIG. 2. Estimativa do potencial de rendimento da cultivar de soja FT Saray, em dois espaçamentos entre linhas (a) e duas populações de plantas (b) nos estádios de florescimento $\left(\mathbf{R}_{2}\right)$, início do enchimento de grãos $\left(R_{5}\right)$, e maturação $\left(\mathbf{R}_{8}\right)$. EEA/UFRGS, Eldorado do Sul, $\mathbf{R S}$, 1996/97. Médias com a mesma letra em cada estádio fenológico, não diferem a $5 \%$ de probabilidade pelo teste de Tukey. 
entes. Segundo Hass (1997), grande parte dos nutrientes adicionados ao solo não é aproveitada por motivos como lixiviação, insolubilização e volatilização, estimando-se o índice de aproveitamento de fertilizantes em 5\% a $20 \%$ para o $\mathrm{Pe} 50 \%$ a $70 \%$ para o K. Embora o teor de P observado inicialmente no solo (10 ppm, considerado médio pela análise de solo) não fosse o mais adequado, as condições de precipitação e possibilidade de suplementação hídrica podem ter favorecido os mecanismos de suprimento de íons e podem ter feito com que os teores médios de P não fossem limitantes. Deve-se somar ainda a esse fator, o teor elevado de $\mathrm{K}$ presente no solo, que apresentou média de 174 ppm (Tabela 1).

Tanto a variação na população de plantas quanto no espaçamento entre linhas não afetaram o potencial de rendimento estimado no estádio $\mathrm{R}_{2}$. Já em $\mathrm{R}_{5}$, $20 \mathrm{~cm}$ de espaçamento foi superior a $40 \mathrm{~cm}$, e 40 plantas $\mathrm{m}^{-2}$ superou 30 plantas $\mathrm{m}^{-2}$. Tal supe-rioridade observada em $\mathrm{R}_{5}$ refletiu-se em $\mathrm{R}_{8}$, no qual foi alcançado maior rendimento com $20 \mathrm{~cm}$. O rendimento em $\mathrm{R}_{8}$, embora maior com 40 plantas $\mathrm{m}^{-2}$, não diferiu estatisticamente do obtido com 30 plantas $\mathrm{m}^{-2}$ (Fig. 2).

A redução no potencial de rendimento, entre os estádios $\mathrm{R}_{2}$ e $\mathrm{R}_{5}$, foi de $26 \%$ para o espaçamento de $20 \mathrm{~cm}$, e de $36 \%$ para o de $40 \mathrm{~cm}$. De $\mathrm{R}_{5}$ para $\mathrm{R}_{8}$ ocorreram reduções de $49 \%$ para $20 \mathrm{~cm}$, e de $48 \%$ para

TABELA 1. Características do solo onde foi realizado o experimento. EEA/UFRGS, Eldorado do Sul, RS, 1996'.

\begin{tabular}{lc}
\hline Característica & Valor \\
\hline Teor de argila (\%) & 25 \\
pH (em água) & 5,0 \\
Índice SMP & 6,1 \\
Fósforo $\left(\mathrm{mg} \mathrm{L}^{-1}\right)$ & 10 \\
Potássio $\left(\mathrm{mg} \mathrm{L}^{-1}\right)$ & 174 \\
Alumínio Trocável (cmol L & ) \\
Matéria orgânica - \% (mv) & 0,3 \\
${ }^{1}$ Análise efetuada no Laboratório de Análise de Solos da Faculdade de \\
Agronomia da UFRGS.
\end{tabular}

$40 \mathrm{~cm}$ de espaçamento (Fig. 2a). A redução na população de plantas, de 40 para 30 plantas $\mathrm{m}^{-2}$, ocasionou decréscimo no potencial de rendimento de $38 \%$, de $R_{2}$ para $R_{5}$, e de $45 \%$, de $R_{5}$ para $R_{8}$. Quando se utilizou a população recomendada (40 plantas $\mathrm{m}^{-2}$ ) essa redução foi de $25 \%$, de $\mathrm{R}_{2}$ para $\mathrm{R}_{5}$, e de $51 \%$, de $\mathrm{R}_{5}$ para $\mathrm{R}_{8}$ (Fig. 2b).

Quando se avaliaram as estruturas reprodutivas (flores e legumes), verificou-se que o número de flores em $R_{2}$ e $R_{5}$ não foi influenciado pela população de plantas ou espaçamento entre linhas, demonstrando que a modificação na competição entre as plantas, proporcionada pelas variações de população e espaçamento, não foram suficientes para afetar o número de flores na comunidade de plantas (Fig. 3). Tal fato pode ser explicado em virtude de as flores serem estruturas que despendem pouca quantidade de assimilados durante seu desenvolvimento (Loomis \& Connor, 1992). Com relação aos legumes, verificou-se que a redução no espaçamento proporcionou aumento em $R_{8}$, mas não houve efeito em $R_{5}$. A redução na população de plantas reduziu significativamente o número de legumes em $\mathrm{R}_{5}$ e $\mathrm{R}_{8}$ (Fig. 3).

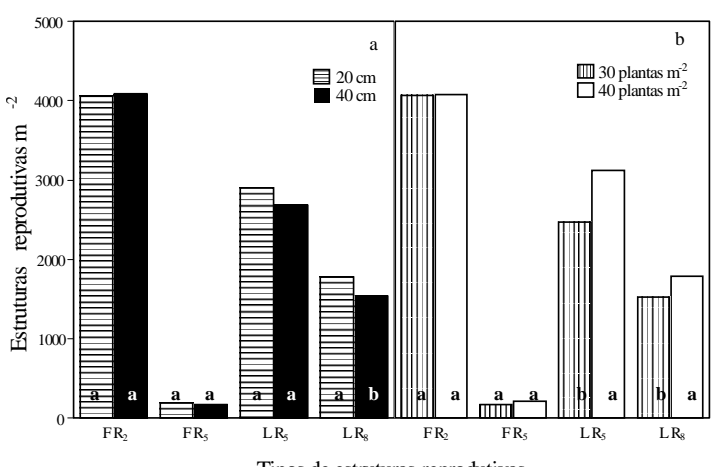

FIG. 3. Número de flores (F) e legumes (L), de soja cultivar FT Saray, em dois espaçamentos entre linhas (a) e duas populações de plantas (b), nos estádios de florescimento $\left(\mathbf{R}_{2}\right)$, início do enchimento de grãos $\left(R_{5}\right)$ e maturação $\left(R_{8}\right)$. EEA/UFRGS, Eldorado do Sul, RS, 1996/97. Médias com mesma letra, em cada tipo de estrutura reprodutiva, não diferem a $5 \%$ de probabilidade pelo teste de Tukey. 
Essas respostas indicam que, para espaçamento, o que comanda a produção ou retenção de legumes é a competição entre plantas, uma vez que o aumento da competição em $40 \mathrm{~cm}$, pelo adensamento das plantas na linha, diminuiu o número de legumes. Isso pode reforçar a hipótese da limitação nutricional exemplificada por Heitholt et al. (1986).

No que se refere à população de plantas, observou-se que, nos estádios iniciais de formação das estruturas reprodutivas, $R_{2}$ e $R_{5}$, a redução da população não permitiu compensar o número de legumes $\mathrm{m}^{-2}$ produzidos pela população de 40 plantas $\mathrm{m}^{-2}$ (Fig. 3b). Após $\mathrm{R}_{5}$, deve aumentar a competição entre as plantas pelos fatores diretamente relacionados ao rendimento de grãos, reduzindo a capacidade produtiva individual das plantas sob maiores populações, tendendo a se aproximar os rendimentos entre as populações (Fig. 2b).

Avaliando-se o número de legumes com um, dois, três e sem grãos, em $\mathrm{R}_{8}$, pôde-se verificar que, além do maior número de legumes $\mathrm{m}^{-2}, 20 \mathrm{~cm}$ foi superior a $40 \mathrm{~cm}$ em legumes com dois e três grãos, não diferindo em legumes com um grão e sem grãos. A população de 40 plantas $\mathrm{m}^{-2}$ superou 30 plantas $\mathrm{m}^{-2}$ no número de legumes com um, dois grãos e sem grãos, não havendo diferença em legumes com três grãos (Fig. 4). Este último efeito demonstra que a população de 40 plantas $\mathrm{m}^{-2}$ possuía maior número de legumes para encher, ou seja, maior número de legumes sem grãos; em condições mais favoráveis que as observadas, essa população poderia ter proporcionado rendimentos superiores.

O peso do grão (expresso em peso de 100 grãos) não variou em legumes com um, dois e três grãos (Fig. 5).

Esses resultados, da mesma forma que os obtidos por Ventimiglia et al. (1999), demonstram que além de proporcionar maior rendimento em $\mathrm{R}_{8}$, a redução no espaçamento de 40 para $20 \mathrm{~cm}$ proporciona maior potencial de rendimento, principalmente no início do enchimento de grãos, possibilitando a obtenção de rendimento elevado se as condições de solo e meteorológicas forem favoráveis.

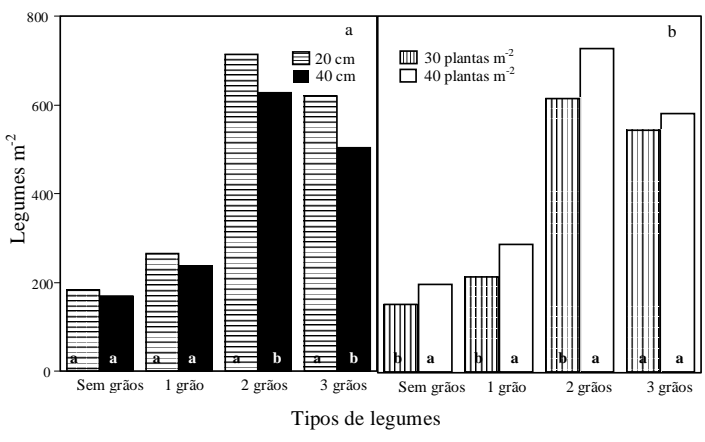

FIG. 4. Número de legumes sem grãos e com um, dois e três grãos da cultivar de soja FT Saray, em dois espaçamentos entre linhas (a) e duas populações de plantas (b). EEA/UFRGS, Eldorado do Sul, RS, 1996/97. Médias com mesma letra, em cada tipo de legume, não diferem a $5 \%$ de probabilidade, pelo teste de Tukey.

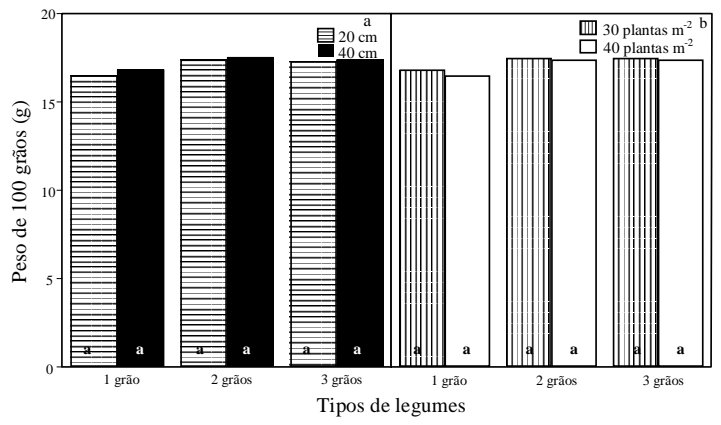

FIG. 5. Peso de 100 grãos ( $13 \%$ de umidade) de legumes com um, dois e três grãos da cultivar de soja FT Saray, em dois espaçamentos entre linhas (a) e duas populações de plantas (b). EEA/UFRGS, Eldorado do Sul, RS, 1996/97. Médias com mesma letra, em cada tipo de legume, não diferem a $5 \%$ de probabilidade, pelo teste de Tukey.

\section{CONCLUSÕES}

1. A variação no espaçamento e na população de plantas modificam o potencial de rendimento da soja durante a ontogenia.

2. O potencial de rendimento é influenciado pela produção, fixação e transformação em legumes com grãos, de estruturas reprodutivas. 
3. Com a utilização do espaçamento de $20 \mathrm{~cm}$ é possível reduzir a perda de potencial de rendimento a partir do estádio $\mathrm{R}_{5}$, resultando em maior rendimento em $R_{8}$ em relação ao espaçamento de $40 \mathrm{~cm}$.

4. A utilização de 40 plantas $\mathrm{m}^{-2}$ diminui a perda de potencial durante a ontogenia, mas não resulta em rendimentos ao final do ciclo superiores aos obtidos com 30 plantas $\mathrm{m}^{-2}$.

\section{REFERÊNCIAS}

BARTZ, H.R. (Coord.). Recomendações de adubação e calagem para os Estados do Rio Grande do Sul e de Santa Catarina. Passo Fundo : Sociedade Brasileira de Ciência do Solo, 1994. 224p.

BUGBEE, B.G.; SALISBURY, F.B. Exploring the limits of crop productivity. Plant Physiology, Rockville, v.88, n.3, p.869-878, 1988.

CAMARGO, M.B.P. de; MIRANDA, M.A.C. de; PEDRO JÚNIOR, M.J.; PEREIRA, J.C.V.N.A.; MASCARENHAS, H.A.A. Estimativa da produtividade potencial de cultivares de soja nas condições climáticas de Ribeirão Preto, SP. Bragantia, Campinas, v.47, n.2, p.277-288, 1988.

COSTA, J.A. Cultura da soja. Porto Alegre : I. Manica \& J. A. Costa, 1996. 233p.

COSTA, J.A.; MARCHEZAN, E. Características dos estádios de desenvolvimento da soja. Campinas : Fundação Cargill, 1982. 30p.

DOORENBOS, J.; KASSAM, A.H. Efectos del água sobre el rendimiento de los cultivos. Roma : FAO, 1979. 71p.
EMBRAPA. Centro Nacional de Pesquisa de Solos (Rio de Janeiro, RJ). Sistema brasileiro de classificação de solos. Brasília : Embrapa-SPI, 1999. 412p.

HASS, F.D. Plantio direto: fatores que interferem na eficiência da adubação. In: FRIES, M.R.; DALMOLIN, R.S.D. (Coord.). Atualização em recomendação de adubação e calagem: ênfase em plantio direto. Santa Maria : UFSM, 1997. p.125-131.

HEITHOLT, J.J.; EGLI, D.B.; LEGGETT, J.E. Characteristics of reproductive abortion in soybean. Crop Science, Madison, v.26, p.589-595, 1986.

LOOMIS, R.S.; CONNOR, D.J. Crop ecology: productivity and management in agricultural systems. Cambridge, Grã-Bretanha : Cambridge University Press, 1992. 520p.

LOOMIS, R.S.; WILLIAMS, W.A. Maximum crop productivity: an estimate. Crop Science, Madison, v.3, n.1, p.67-72, 1963.

MARCHEZAN, E. Produção e fixação de flores e legumes, por nó do caule e dos ramos, em três cultivares de soja. Porto Alegre : UFRGS, 1982. 105p. Dissertação de Mestrado.

OMETO, J.C. Bioclimatologia vegetal: balanço hídrico. São Paulo : CERES, 1981. 425p.

SINCLAIR, T.R. Limits to crop yield? In: BOOTE, K.J. (Ed.). Physiology and determination of crop yield. Madison : American Society of Agronomy/Crop Science Society of America/Soil Science Society of America, 1994. p.509-532.

VENTIMIGLIA, L.A.; COSTA, J.A.; THOMAS, A.L.; PIRES, J.L.F. Potencial de rendimento da soja em razão da disponibilidade de fósforo no solo e dos espaçamentos. Pesquisa Agropecuária Brasileira, Brasília, v.34, n.2, p.195-199, fev. 1999. 